This is an electronic reprint of the original article. This reprint may differ from the original in pagination and typographic detail.

Author(s): Myllymäki, Mikko; Hakala, Ismo; Härmänmaa, Tuomo; Laine, Sanna

Title: $\quad$ Flipped Learning Experiment in Video-Based Education

Year: $\quad 2017$

Version:

Please cite the original version:

Myllymäki, M., Hakala, I., Härmänmaa, T., \& Laine, S. (2017). Flipped Learning Experiment in Video-Based Education. In L. G. Chova, A. L. Martínez, \& I. C. Torres (Eds.), EDULEARN17 Proceedings. 9th International Conference on Education and New Learning Technologies (pp. 2415-2424). IATED Academy. EDULEARN Proceedings. https://doi.org/10.21125/edulearn.2017.1502

All material supplied via JYX is protected by copyright and other intellectual property rights, and duplication or sale of all or part of any of the repository collections is not permitted, except that material may be duplicated by you for your research use or educational purposes in electronic or print form. You must obtain permission for any other use. Electronic or print copies may not be offered, whether for sale or otherwise to anyone who is not an authorised user. 


\title{
FLIPPED LEARNING EXPERIMENT IN VIDEO-BASED EDUCATION
}

\author{
Mikko Myllymäki, Ismo Hakala, Tuomo Härmänmaa, Sanna Laine \\ University of Jyväskylä (FINLAND)
}

\begin{abstract}
One of the most important reasons for utilising virtual environments is to increase the flexibility of participating in education. Videos are a widely utilised technological solution for realising this type of flexible education. An educational model that videos are especially well suited for is flipped learning. However, the absence of contact teaching poses challenges for flipped learning, in which traditionally lecture-heavy activities are arranged as self-studies while face-to-face classes are used for cooperative studying. This paper examines a piloting of flipped learning organised alongside a videobased blended education model. The pilot provides experience of how flipped learning functions in an educational environment where the flexibility of participation is a priority, participation is mostly done asynchronously using on-demand videos, and in which students make practically no use of contact teaching. Based on the observations, the paper's discussion section presents some noteworthy considerations, as well as possible solutions for challenges identified during the piloting.
\end{abstract}

Keywords: blended learning, flipped learning, video lecture.

\section{INTRODUCTION}

Videos intended for educational use have increased significantly in recent years. This is partly due to the increasing use of videos for entertainment purposes, as well as an increase in broadband connections. Educational videos may include short video clips, screen capture videos or, for example, recordings from classroom teaching situations. Videos can be utilised in revision, compensating for absences, making teaching more flexible, or developing presentation skills. Lecture recordings can also be re-used later. This enables completely new types of educational solutions, such as flipped learning, to be implemented.

In flipped learning, activities traditionally carried out in class, for example lectures, are transferred from a group learning space into an individual learning space. Time can then be used for other beneficial educational activities, like collaborative learning in a group space. The idea behind flipped learning is a student-oriented approach, where the focus and responsibility for learning are shifted from the instructor onto the student.

In connection with the master's degree programme of mathematical information technology in Kokkola University Consortium Chydenius, videos have been used for studying for a number of years. All teaching is offered to students as face-to-face teaching and in the form of live videos and on-demand videos. Students can freely choose to participate in each lecture the way that suits them best. In recent years, it has been noticed that participation with the help of videos is increasingly emphasised while the role of classroom education has decreased. This means that in a video-based education model, where students are willing to participate independently of time and place, flipped learning, which emphasises interactivity and collaborative work, is challenging to implement.

In 2016, the Data Networks course was arranged using a flipped learning model by utilising lecture videos from previous courses. The implementation of the course provided experiences and feedback about the functionality of the solution. It also presented some challenges related to the implementation of flipped learning in a video-based environment.

In this paper, the opportunities and challenges that a video-based education model sets for the implementation of flipped learning are discussed in more detail. The paper examines the realisation of the Data Networks course, and the experiences and feedback gathered in connection with it. The realisation is evaluated with the help of information provided by the media server log data. The implementation is also compared to previous times the course was organised, which were more reliant on traditional lectures. 


\section{BACKGROUND}

\subsection{Videos in Education}

Videos have become more widely used in education over the past few years. This has partly been influenced by videos also being watched more often in everyday life. Technologies that students already utilise in their free time quickly become a natural part of education as well. Another factor that has had a notable effect on the use of videos is the proliferation of broadband internet connections [1].

Educational videos can be implemented in a variety of ways; they can be short video clips, long lecture recordings, or anything in between. They can also be either live streams or on-demand videos. Live videos can feature interaction between participants, although educational videos can often also be unidirectional with no interactivity involved. Videos can also be produced in contact teaching situations or studio environments. Furthermore, videos can be recorded directly from a teacher's computer using screen capture software.

Videos can be used in a number of ways to make teaching more versatile. Kay [1] divides videos into four categories based on their purpose of use. Lecture-based videos are recordings of entire lessons that students can watch instead of or after participating in contact teaching. Enhanced video presents the slides used as teaching materials with additional voice-over narration. Supplementary videos expand on the teaching by offering extra materials, such as real-world examples, summaries of text book chapters or other supplementary materials that enhance teaching. Finally, worked examples are explanations in video form for specific problems that students are presented with during courses.

The biggest difference between studying with videos and contact teaching is the level of interaction involved. With the help of technological solutions, interaction can be made to resemble a contactteaching situation. Elements that support interaction can be devised to complement live videos. When using on-demand videos, interaction must be realised for example by using asynchronous discussion forums. On the other hand, on-demand videos allow students to choose the time and place for studying based on their personal needs. With the use of on-demand videos, students can break the learned topics into suitable portions and pace their studies as they wish. Among other things, they can take a break to reflect on the studied topic, make notes, or write summaries. While watching recordings, students can also rewind difficult sections as many times as they want.

Winnips et al [2] have described the various benefits that lecture videos provide. According to them, videos can be naturally used for revising contact-teaching situations in order to learn difficult parts or to practise for exams, for instance. Another way of utilising videos they suggest is substituting for absences. Students are given access to course materials when they have been unable to attend contact teaching due to e.g. scheduling issues or illness. Organisers can also hand out supplementary materials, such as video clips, for completing learning tasks or use videos to provide additional information to support lectures. Furthermore, students can watch their own presentations on video in order to develop their presentation skills, which of course applies to teachers as well. Lecture videos can also be reused on other courses or with a different group of students.

Overall, videos can be produced and utilised in a variety of ways. Besides supporting regular teaching, videos enable the realisation of entirely new educational solutions, such as blended learning and flipped learning.

\subsection{Blended Learning}

There have been multiple suggestions for the definition of blended learning, but according to a commonly accepted one it is seen as a combination of face-to-face and online instructions [3][4]. In blended learning, teaching tied to a location and time (such as traditional classroom teaching) is blended with teaching that is independent of place (e.g. live lecture videos) and possibly also time (e.g. on-demand videos). There have been various definitions regarding what to call education where a portion of the teaching is organised online [5][6].

The motivation for blending education is usually that it is seen to combine the best sides of both faceto-face and online instructions [7]. Examining the issue more closely, reasons that can identified for organising blended learning include better pedagogical practices, improved flexibility and accessibility, as well as cost-efficiency [8]. A term used to describe blended learning models where the primary objective is to improve accessibility of education is enabling blends [9]. These models utilise a variety of methods in attempting to provide students with largely the same opportunities and studying experiences as traditional teaching does. Blended learning models that see some changes to 
pedagogical practices, although without radically altering what is being taught and learned, are called enhancing blends [9]. Examples of this type are supplementary online learning materials and other web-based education solutions. Finally, transformative blends allow even radical pedagogical changes to be made. Models of this type typically utilise teaching solutions that would not be possible without technology. One such example is education in which students act as active builders of information by utilising various technological solutions that increase the interactivity of a network. Blended learning solutions can also overlap between these categories.

\subsection{Flipped Learning}

One of the main reasons for blending learning is to have more versatile options for pedagogical solutions. A blended model enables courses to be organised in entirely new ways. An example of such an approach is flipped learning, which works especially well with videos [10][11][12]. Flipped learning is a pedagogical approach in which learning materials are handed out to students before a contact teaching class. Traditional classroom activities, such as lectures, are made possible to study at home using for example videos, whereas activities that have typically been done at home, such as homework, are performed in class [13]. Teaching can be realised, for instance, by having students watch lecture videos at home and do practice calculations that have typically been assigned as homework in class with other students and the teacher [e.g. 14].

Flipped learning does not only alter the time and place of learning, but also introduces a change towards more collective learning, in which students can benefit from each other in their own studies. Flipped learning is based on the constructivist view of learning, according to which learning is done when a student actively processes information by e.g. discussing, doing tests, tasks etc. This way, new information is added on top of existing information structures [15]. The focus and responsibility for learning are shifted from the teacher onto the student. The teacher's role changes from sharing information to supporting self-guidance.

In other words, flipped learning aims to turn class time from passive work towards focusing on active student participation. In K-12 education, time is recommended to be reserved for individual practice, such as problem solving [16]. The recommendation in regard to higher education is to emphasise the application of course contents [17]. This way, class time also offers the teacher a better opportunity to identify students' false reasoning [18].

With flipped learning emphasising classroom activities and communality, is it then possible to realise this type of cooperative work in a virtual learning environment, which might not include any contact teaching and in which students participate in education according to their own schedules?

\section{FLIPPED LEARNING EXPERIMENT}

Lecture videos are a natural part of studying at Kokkola University Consortium Chydenius' master's degree programme in mathematical information technology. All teaching has traditionally been organised as contact teaching, with lecture videos being produced of these classes. The diminished role of contact teaching has led the organisation to seek new solutions for realising teaching.

\subsection{The Environment}

Blended education has been organised as a part of the master's degree programme for a long time. All students in the degree programme are adult students, most of whom have jobs and families. For students like these, scheduling can be extremely challenging, as they must make compromises between studying, work and family. Most of all this can be seen in the form of difficulties in participating in the offered education. In the education programme, flexibility in participation has been for a long time improved by offering all education also as lecture videos. All the organised teaching has been realised as contact teaching, which has been recorded and offered to students as live videos and on-demand videos. Students have been able to freely choose their mode of participation between face-to-face lecture, live video and on-demand video on a lecture-to-lecture basis.

A video distribution application called CiNetCampus Studies was developed to enhance the educational use of videos. One of the goals of the application was to improve interaction possibilities and communality in studying with videos. With the application, students can see who else are participating in lecture and also to communicate with the lecturer and each other using the integrated chat function. 
Studying with the use of videos has become an essential and natural part of studying in the degree programme over the years. Fig. 1 describes the proportions of different participation modes in 2017. As the figure illustrates, today live videos and on-demand videos have a very significant role. The diminished role of face-to-face teaching has gotten the educational organisation to re-evaluate the meaningfulness of contact teaching and also to look into ways to improve the utilisation of videos from a pedagogical standpoint. Because of this, various pedagogical solutions, such as flipped learning, have been tested. Low participation rates in contact teaching and on the other hand the large amount of students using videos poses challenges for realising education in accordance with the flipped model, as it typically emphasises contact teaching, interactivity, and communal working.

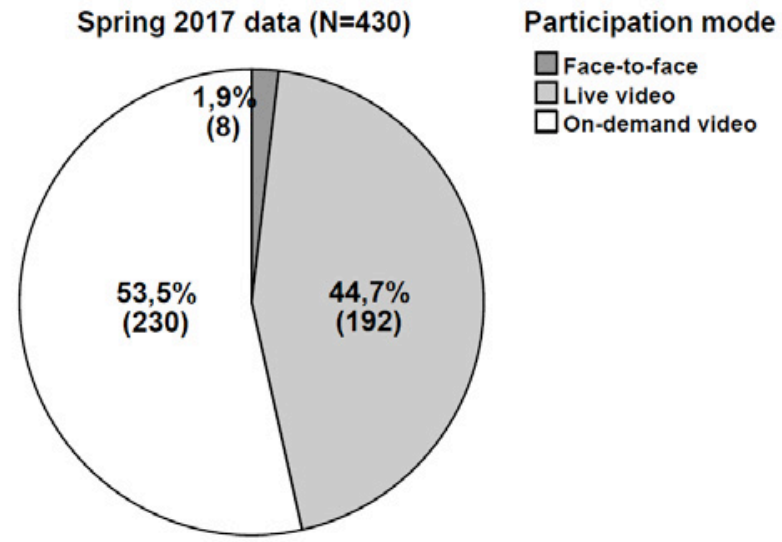

Figure 1. The Proportions of participation modes in 2017

\subsection{Implementation of Flipped Learning in The Data Networks Course}

The Data Networks course has previously been organised as video-based blended learning. All lectures during the course were organised as contact teaching, in addition to which students were able to participate using live videos and on-demand videos. They could decide their own participation mode and thus determine the ratio of video-based studying and contact classes during the course. In other words, the students themselves were able to determine the degree of blending on the course. There has been a notable drop in the amount of students attending contact teaching over the years when the Data Networks course has been organised. Nearly all students participated in the education by watching on-demand videos at a time that suits them, making the course more of a self-study option. During previous times the course has been organised, it has been noted that students do not usually take the final exam at the end of the course. Instead, they take the exam at varied times throughout the year. The objective of examining the reuse of lecture videos was to change the way the course is realised.

By reusing previous lecture recordings, the course was transformed into a flipped learning solution. Students in the degree programme were already used to utilising the videos extensively and on the other hand, some of the students lived far enough away from the campus area to make attending contact teaching practically impossible. That is why, it was obvious from the start, that many students would not attend classes in person even if the contents of contact teaching were changed to be more communal and to emphasise learning by doing. Then again, the aim was also to avoid having the education solution diminish the flexibility of participation on the course in question. Flexible studying methods are a significant basic principle behind all teaching organised as a part of the degree programme.

In the flipped learning experiment, the contact teaching element was to be replaced with collaborative sessions. The idea was to offer students lecture videos from the previous year at a specific pace for self-studying. Another goal was to organise collaborative teaching situations that students could attend in person or via live video.

The course of 2016 made use of lecture videos from the previous time the course was held, and the videos were distributed to the students according to the schedule of the previous course. This was to ensure that student would have the opportunity to internalise the videos' materials before the next video would be published. In practice, students gained access to the new lecture videos on Wednesdays. The course took place over the winter, and there was a longer break during Christmas and New Year's holidays. 
Before the publication of every new video on Wednesdays, the lecturer held a shorter collaborative session which had two purposes. The first of these was to elaborate on difficult topics in the previous week's lecture video. In regard to this, students were given an opportunity to ask questions and bring up unclear topics from the previous week's lecture before the weekly collaborative session. This was carried out using the Learning Management System's discussion forums. The deadline for questions was Monday. The lecturer then had the opportunity to provide extra tuition and go through the difficult topics during the collaborative session. The other purpose of the collaborative sessions was to provide a fairly short introduction for the upcoming lecture video and to highlight the central topics of the lecture. Students were able to attend the collaborative sessions in person or by using live video. A channel of interaction was available in conjunction with the live videos, providing students an opportunity to discuss with each other or the lecturer. From an interaction standpoint, the solution is an example of flipped learning, even though the students were able to participate virtually instead of in person. Sessions were also offered as on-demand videos. The implementation of the course is illustrated in Fig. 2.

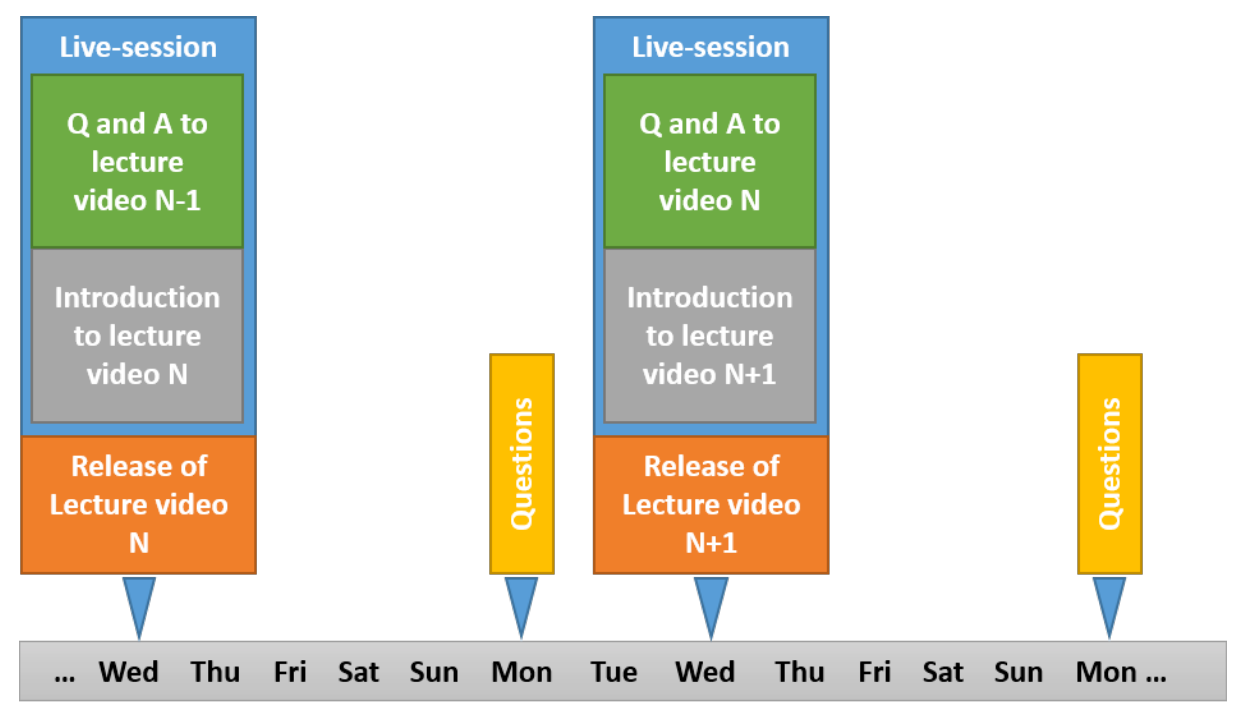

Figure 2. Implementation of the course

The purpose of the changes was to encourage more activity among students during the course. Previously, most students completed the course practically at their own pace by using on-demand videos. The weekly introduction videos were intended to pace the teaching. The large portion of participations using on-demand videos during previous times the course was held was indicative of students' views that the contents of contact teaching classes were not considered to provide enough meaningful additional value to warrant participating in them in real time or even by following the lectures' schedule. In the new course strategy, the purpose was to provide this additional value by focusing on difficult topics in contact teaching. Furthermore, revision of challenging topics from previous collaborative sessions and the introductions to upcoming topics were hoped to improve learning outcomes.

The piloting sought to answer the following questions:

- Did the collaborative sessions pace studying as planned?

- Were the collaborative sessions successful in achieving collaborative studying?

- Did the education solution have an effect on exam participation, pass rates and grades?

\section{RESULTS}

Plenty of information was gathered from the course. Extensive log data regarding students' participation modes was gathered on the media server as a result of video views. In addition, the log data was complemented with the results of a course questionnaire handed to the students, as well as course performance results from the university's study attainment register. 
The successfulness of the course's pacing was evaluated by examining students' participation modes. Despite the new implementation, students were still able to complete the course entirely according to their own schedules and in any order. The evaluation focused especially on whether students completed the course in the planned order and schedule illustrated in Fig. 2. An essential matter in regard to scheduling was also to find out if students had time to watch the lecture videos before the deadline for submitting related questions and if they thus had realistic opportunities to utilise the possibility to ask questions. Another interesting consideration in the new implementation was naturally also to examine the role of the collaborative sessions; to what extent were the introductions watched and on the other hand, if the introductions were watched before their associated contact teaching class. Examination of the role and significance of the collaborative sessions also provided viewpoints into the successfulness of communal learning during the course. Learning results were examined in relation to course pass rates and grades.

While analysing the use of videos, it was observed that lectures were clearly viewed in order (lecture 1 was watched before lecture 2, lecture 2 before lecture 3, etc.). As many as $99 \%(n=95)$ of the lecture video viewings were conducted like this. Participation in collaborative sessions was also clearly more heavily reliant on on-demand videos. Almost no students participated in contact teaching classes during collaborative sessions, and only two students used live videos during the first two sessions. Even though real-time participations in collaborative sessions were scarce, $66 \%$ of lecture views $(n=86$, one lecture had no video introduction) were conducted by viewing the introduction before the corresponding lecture.

The pace of watching lecture videos in relation to the deadline for submitting related questions is illustrated in section B of Fig. 3. As the figure shows, around $55 \%$ of the time $(n=84)$ videos were watched before the deadline for submitting the questions. In practice, in roughly half of the cases students had an opportunity to ask questions related to the lecture videos.

The pace of watching lecture videos in relation to the next lecture is presented in section C of Fig. 3. Lecture videos were watched before the release of next lecture $67 \%(n=84)$ of the time and the rest $33 \%$ only after the release of next lecture video (Fig. 3D). $12 \%$ of the time, lecture videos were watched before the next lecture was held but after the deadline for submitting questions had expired (Fig. 3A).

As Table 1 shows, there were notable differences between students' studying habits. There were students who almost always watched lecture videos before the release of next lecture video and usually also before the deadline for the questions. On the other hand, some students followed this pace rarely or not at all.

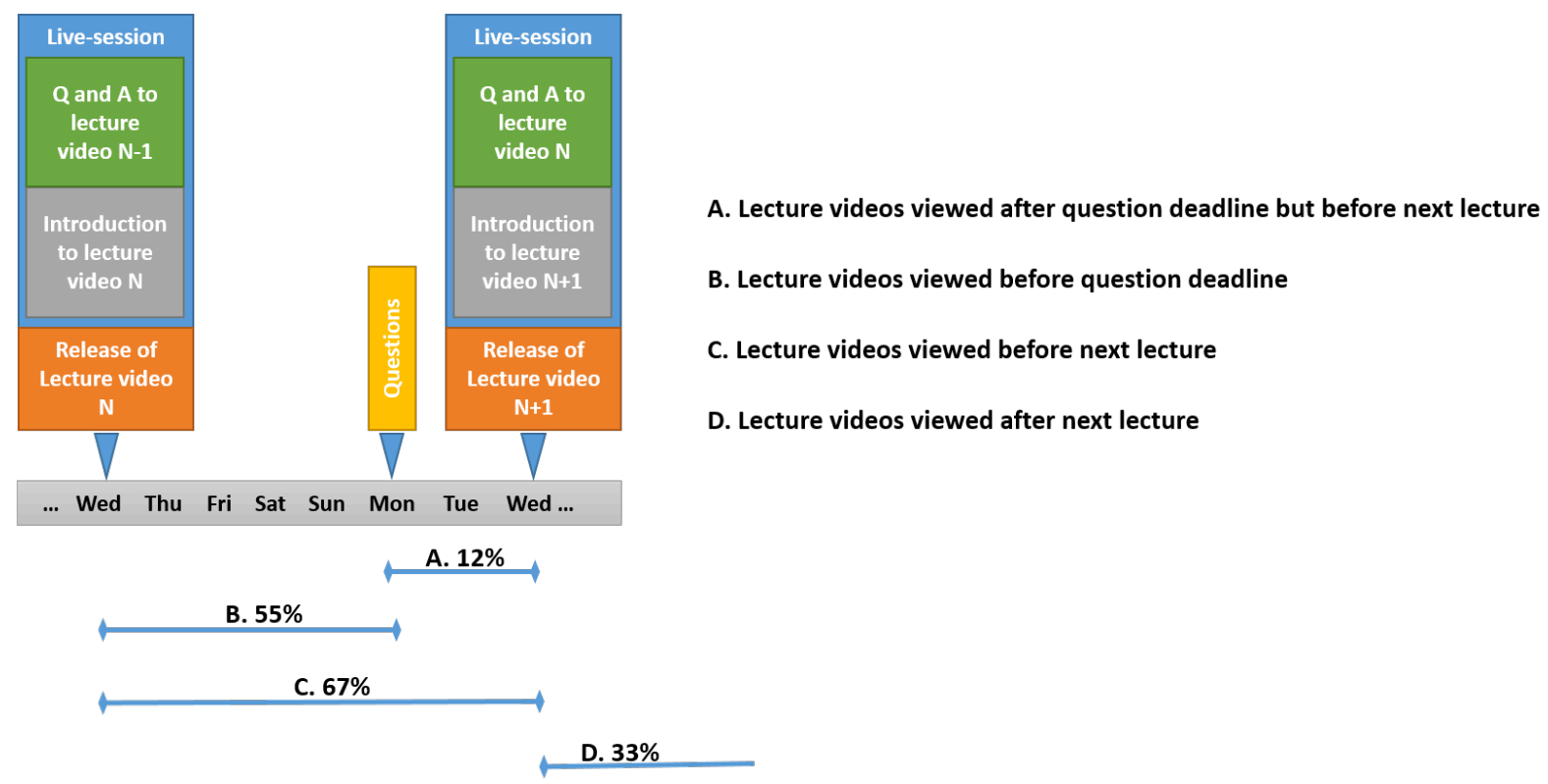

Figure 3. Viewing of lecture videos in relation to question deadlines and the next lecture 
Table 1. The pace of students' lecture video viewing.

\begin{tabular}{|l|c|c|c|c|c|c|}
\hline & $\begin{array}{c}\text { Number of } \\
\text { collaborative } \\
\text { sessions viewed } \\
\text { (max=8) }\end{array}$ & $\begin{array}{c}\text { Number of } \\
\text { collaborative } \\
\text { session } \\
\text { reviewed } \\
\text { before exam }\end{array}$ & $\begin{array}{c}\text { Number } \\
\text { of } \\
\text { lecture } \\
\text { videos } \\
\text { viewed } \\
\text { (max=9) }\end{array}$ & $\begin{array}{c}\text { Number of } \\
\text { lecture videos } \\
\text { viewed before } \\
\text { question } \\
\text { deadline } \\
\text { (max=8) }\end{array}$ & $\begin{array}{c}\text { Number of } \\
\text { lecture videos } \\
\text { viewed before } \\
\text { next lecture } \\
\text { (max=8) }\end{array}$ & $\begin{array}{c}\text { Grade } \\
\text { on the } \\
\text { st } \\
\text { exam }\end{array}$ \\
\hline Student 1 & 2 & 1 & 8 & 0 & 0 & 1 \\
\hline Student 2 & 8 & 2 & 9 & 0 & 2 & 3 \\
\hline Student 3 & 8 & 3 & 8 & 2 & 2 & 5 \\
\hline Student 4 & 7 & 4 & 7 & 2 & 2 & 2 \\
\hline Student 5 & 8 & 0 & 9 & 3 & 4 & FAIL \\
\hline Student 6 & 8 & 7 & 9 & 5 & 6 & 3 \\
\hline Student 7 & 7 & 0 & 9 & 5 & 8 & 3 \\
\hline Student 8 & 8 & 8 & 9 & 6 & 8 & 4 \\
\hline Student 9 & 8 & 3 & 9 & 7 & 8 & 1 \\
\hline Student 10 & 8 & 1 & 9 & 8 & 8 & 3 \\
\hline Student 11 & 8 & 0 & 9 & 8 & 8 & 5 \\
\hline Averages & 7.3 & 2.6 & 8.6 & 4.1 & 5.1 & 3 \\
\hline
\end{tabular}

Examining the significance of the introductions and the Q\&A sessions in Table I shows that ten students watched almost every collaborative session, while one student watched lecture videos, but very few collaborative sessions. In a questionnaire sent to students, all respondents $(n=6)$ thought the working methods were expedient for the course, and $83 \%$ felt that the course supported their learning well. Likewise $83 \%$ thought the collaborative sessions were useful for course completion. As previously stated however, participations using live video were rare and active student participation could not be realised during collaborative sessions. There were also fewer questions about difficult topics than expected; only three questions were submitted. In the end, the role of collaborative sessions was having the lecturer go over complicated topics, as well as providing introductions for upcoming lectures. Collaborative sessions could also be used for revision. Three students watched four or more collaborative session recordings they had already seen before taking the exam, and only three students did not rewatch any sessions (Table 1).

When analysing course pass rates, it was observed that all 11 active students also participated in the final exam, and that the pass rate was very high (91\%). The average grade was 3 on a scale of $1-5$. A clear difference can been seen compared to previous times the course was organised, when only a small portion of active students participated in the final exam and mainly took substitutive exams at a later date instead. The pass rates and grades were also distinctly much weaker during previous courses (2012: pass rate $66 \%$, average grade 2.5 and 2014: pass rate $40 \%$, average grade 1.5 ).

Based on these results, collaborative sessions can be said to have paced course participation. Some students clearly attempted to study following the planned schedule, while on the other hand, there were also students who were unable to take advantage of the opportunity to ask questions, as they watched the lecture videos after the question deadline had expired. There is no definite data available regarding whether this was because the schedule between publishing the videos and the deadline for the questions was too strict, or because of students' studying behaviour. Participation in collaborative sessions in real time was nearly nonexistent. The sessions could have also been attended in person, but this option went unused by students as well. This naturally had an effect on how the collaborative sessions turned out in regard to revising difficult topics, which was done in lecture format. Realising collaborative activities was not possible in practice. However, students considered the possibility to ask questions, revise difficult topics and the lecture video introductions to be beneficial, even though only very few questions were submitted. It should be noted here that the course in question was a basic level course, whose contents were not particularly challenging. This might have affected the relative lack of unclear topics. The learning outcomes on the other hand were very positive, especially in regard to passing the course. Compared to previous courses, students also completed the course relatively quickly after it finished, instead of spreading the course completion over the year. 


\section{DISCUSSION}

The most significant challenges of flipped learning organised in a video-based virtual environment are related to real-time participation and activating the students. This is especially emphasised when the purpose of virtualising education has been to maximise flexibility. In this type of education, students are typically used to participating in accordance with their own needs, e.g. using video technologies. In an education programme like this, contact teaching may not have much of a role.

The lack of contact teaching is problematic for traditional flipped learning, which emphasises using class time for applying learned topics and collaborative work instead of lectures. Contact teaching related to time and place can in virtual learning environments be substituted with real-time participation, realised with the use of e.g. live videos. In order to use live videos in flipped education, they must be accompanied with functional technological solutions that enable collaborative studying. A possible problem with this type of realisation is that real-time participation can restrict the flexibility of participation temporally. In relation to the examined course, this was exhibited in the form of students who were used to studying at their own pace not participating in collaborative sessions even by using live videos. Just being independent of place was thus not enough for flexibility. It is also possible that being able to go over difficult topics was not motivation enough to participate in teaching in real-time.

In order to increase motivation to participate, students should be given e.g. group work tasks in realtime learning situations for conceptualising the learned topics. Doing group work via the internet is difficult, although not impossible, to realise meaningfully using current technologies. Even if constraints regarding place were eliminated, getting students to participate in education simultaneously remains challenging.

In virtual learning environments, collaborative work and interaction could be realised independently of time using various technologies that enable asynchronous communication. The traditional idea of flipped learning, where independent studying (such as watching videos) is followed by interactive and collaborative contact teaching, would be replaced with having independent studying followed by collaborative and interactive asynchronous online work.

Whether collaborative studying is realised in class or online, before doing so it would be useful to hear from students in regard to topics that they found difficult during self-studying. In the examined course such topics were attempted to be identified by giving students the opportunity to ask questions before collaborative sessions. However, this did not prove particularly effective. Student may even find it difficult to put into words what they found difficult. It could be more efficient to assess students' knowledge of the taught topics and base deductions about what types of content are typically found challenging on the results. For instance, students could be asked to keep a small learning diary of their self-studies independently. Based on the diaries, lecturers could make observations about what topics students commonly find challenging, which could then be focused on during collaborative sessions or online work. Alternatively, students' know-how regarding the course materials could be gauged by handing out short, mandatory questionnaire forms. No matter which alternative was chosen, students' motivation to respond to these measures could be improved by including them as a part of the course evaluation.

On the course examined in the study, the schedule was laid out in a way that gave students around five days to watch a lecture video (including weekends) before the deadline for submitting questions would expire. Scheduling can be seen as one of reasons for why $45 \%$ of the time, students watched lecture videos only after the deadline. In other words, the course schedule should be loose enough to allow students plenty of time to go through the materials. A decent length of time between lectures promotes flexible course participation. This way, even busy students have enough time to get to know the materials in the allotted time, participate in course activities such as online discussions and ask questions about difficult topics before the next lecture.

\section{CONCLUSIONS}

Videos have rapidly become more commonly used in education over the past few years. This is partly due to the proliferation of the entertainment use of videos, as well as faster connection speeds. The applicability of videos for educational purposes has also had a significant impact on their implementation. An educational model that videos are especially well suited for is flipped learning. With the use of videos, traditional lectures can be offered as self-study materials, and contact teaching can be dedicated for e.g. collaborative work that focuses on more difficult topics. 
Education is moved more and more towards virtual environments these days. One of the key reasons for utilising virtual environments is to increase the flexibility of participating in education. This is especially important for students who find it challenging to participate in traditional education, such as adults who study alongside work. Virtual environments that emphasise above all the flexibility of participation pose challenges for flipped learning. Such an environment might feature no contact teaching at all, and even synchronous online participation might have a diminished role. However, the implementation of flipped learning can still be based on technological interaction solutions. Collaborative learning can be realised either synchronously or asynchronously based on whether or not students can be prompted to actively participate in real-time teaching.

The flipped learning experiment described in this paper showed that the implementation in question, based on Q\&A sessions and introductions for lecture videos, was a fairly successful solution in many respects. The course was paced by the collaborative sessions that included going over difficult sections from the previous lecture video and providing an introduction to the next one. Results showed faster course completion times and improved course pass rates. However, conclusions regarding learning outcomes still require more extensive research on the topic.

Various other sites of development were also highlighted during the experiment. An operational model in which collaborative sessions focusing on difficult topics were used to augment independent studies using lecture videos was found to be a functional solution. However, having the opportunity to ask questions alone was not enough to motivate students to bring up topics they found challenging. This could be addressed by utilising various activities that gauge students' knowledge, such as small-scale questionnaires or learning diaries, which students would write alongside lecture videos and collaborative sessions. Attention should also be paid to the scheduling of flipped learning courses. Students need to be given enough time to go through the self-study materials in order to find out what topics they find difficult.

If students are given a choice between different modes of participation, they should be motivated to choose ones that take place in real-time. The practices employed in collaborative sessions should make students feel they are being provided with additional value compared to more flexible participation using on-demand videos. One solution regarding education that makes use of virtual studying is to build courses where instead of collaborative sessions, communal learning is realised asynchronously over the internet between the times when students watch lecture videos. This, however, requires technological solutions that enable collaborative online learning.

In the future, the implementation of flipped learning presented in this study will be developed further in connection with various courses, based on the observations made here.

\section{ACKNOWLEDGEMENTS}

The research for this paper was financially supported by the European Social Fund, grant no. S20073, without which the present study could not have been completed. The authors wish to thank the Central Finland Centre for Economic Development, Transport and the Environment for their help.

\section{REFERENCES}

[1] R. H. Kay, "Exploring the use of video podcasts in education: A comprehensive review of the literature," Computers in Human Behavior, vol. 28, no. 3, pp. 820-831, 2012.

[2] J. C. Winnips, G. J. Verheij, and E. M. Gommer. "The Next Step for Use of Streaming Video in Higher Education: Didactic Models for Weblectures," in Streaming Media Delivery in Higher Education: Methods and Outcomes, (C. Wankel and J. Sibley Law, eds.), pp. 39-60, Hershey: IGI Global, 2011.

[3] C. R. Graham, "Emerging practice and research in blended learning," in Handbook of distance education, 3rd ed. (C. D. Dziuban, J. L. Hartman, and P. D. Moskal, "Blended learning," EDUCAUSE Center for Applied Research, Research Bulletin, vol. 2004, no. 7, 2004.

[4] I. E. Allen and J. Seaman, "Online nation: Five years of growth in online learning," Sloan Consortium report, 2007.

[5] J. Watson, A. Murin, L. Vashaw, B. Gemin, and C. Rapp, "Keeping pace with K-12 online learning: An annual review of policy and practice," Evergreen Education Group report, 2010. 
[6] D. E. Sims, C. S. Burke, D. S. Metcalf and E. Salas, "Research-based guidelines for designing blended learning" Ergonomics in Design, vol. 16, no. 1, pp. 23-29, 2008.

[7] C. R. Graham, S. Allen, and D. Ure, "Benefits and challenges of blended learning environments," in Encyclopedia of information science and technology, (M. Khosrow-Pour, Ed.), pp.253-259, Hershey, PA: Idea Group, 2005.

[8] C. R. Graham, "Blended learning systems: definition, current trends and future directions," in Handbook of blended learning: Global perspectives, local designs (C.J. Bonk and C.R. Graham, eds.), pp. 3-21, San Francisco, CA: Pfeiffer Publishing, 2006.

[9] J. Bergmann and A. Sams, Flip your classroom: Reach every student in every class every day. International Society for Technology in Education, 2012.

[10] M. J. Lage, G. J. Platt and M. Treglia, "Inverting the classroom: A gateway to creating an inclusive learning environment," The Journal of Economic Education, vol. 31, no. 1, pp. 30-43, 2000.

[11] B. Sohrabi and H. Iraj, "Implementing flipped classroom using digital media: A comparison of two demographically different groups perceptions," Computers in Human Behavior, vol. 60, pp. 514-524, 2016.

[12] D. Szafir and B. Mutlu, "ARTFuL: Adaptive review technology for flipped learning," in SIGCHI Conference of Human Factors Computer Systems, pp. 1001-1010, 2013.

[13] Y. Chen, Y. Wang and N. S. Chen, "Is FLIP enough? or should we use the FLIPPED model instead?," Computers \& Education, vol. 79, pp. 16-27, 2014.

[14] P. Tynjälä, Oppiminen tiedon rakentamisena: Konstruktivistisen oppimiskäsityksen perusteita. Helsinki: Kirjayhtymä, 1999.

[15] C. G. Prober and S. Khan, "Medical education reimagined: a call to action," Academic Medicine, vol. 88, No. 10, pp. 1407-1410, 2013.

[16] W. J. Pluta, B. F. Richards and A. Mutnick, "PBL and beyond: Trends in collaborative learning," Teaching and learning in medicine, vol. 25, no. sup1, pp. 9-16. 2013

[17] J. O'Flaherty and C. Phillips, "The use of flipped classrooms in higher education: A scoping review," The Internet and Higher Education, vol. 25, pp. 85-95, 2015. 